\title{
Habermas Leitor de Rousseau
}

\author{
Ricardo Monteagudo ${ }^{I}$
}

RESUMO: Pretendemos mostrar um aspecto pelo qual a leitura que Habermas faz de Rousseau, em Mudança estrutural da esfera pública (1962), é levemente revisada em Direito e democracia (1992). Essa pequena mudança, por sua vez, reestrutura toda a concepção habermasiana da política de Rousseau.

PALAVRAS-CHAVE: Habermas. Rousseau. Esfera pública. Opiniāo pública. Direito político.

Jürgen Habermas recorre frequentemente a Rousseau, para comentar e refletir sobre temas contemporâneos. Há três obras importantes em que o Cidadão de Genebra aparece com papel relevante: Mudança estrutural da esfera pública (de 1961), Teoria da ação comunicativa (de 1981) e Direito e democracia entre faticidade e validade (de 1992). Gostaríamos de analisar brevemente a presença de Rousseau, na primeira e na terceira obras. Sabemos que Habermas é pensador da segunda geração da Escola de Frankfurt e que promove uma virada metodológica (tournant méthodologiquel methodological turn ou, ainda, linguistic turn), em que deixa de lado o estilo de Adorno (seu orientador no Instituto de Pesquisa Social de Frankfurt), mais próximo da dialética e do marxismo, e pensa a partir de um sistema de comunicaçáo intersubjetivo, de condiçóes universais para a ação comunicativa. Não se trata de uma nova linguística, mas de uma ética política. Essa virada obriga Habermas a reavaliar o legado de Hegel e Kant e, nesse retorno, reconhece a importância de Rousseau

\footnotetext{
${ }^{1}$ Professor-doutor e orientador no Departamento de Filosofia e no Programa de Pós-Graduação em Filosofia da UNESP.
} 
para o filósofo de Königsberg, embora, segundo o teórico frankfurtiano, este seja mais liberal e o outro mais republicano ${ }^{2}$.

Muitas vezes, Rousseau e Kant são mencionados como teóricos da autonomia do indivíduo e, em ambos, Habermas vê uma intuição comum de intersubjetividade, e em Rousseau, sobretudo, uma teoria da subjetividade no romance epistolar $A$ nova Heloísa e nas obras autobiográficas (Confissóes e Devaneios de um caminhante solitário). É importante também o contraste de ambos com Hobbes, pois este teria excluído a ideia de uma filosofia política cidadã, ou seja, o governo é sempre antidemocrático. Rousseau é visto como um dos pais dos direitos humanos e da soberania popular. Uma das críticas a Hobbes e Grotius é que esses filósofos modernos tomaram o fato como direito e confundiram a força física com o dever moral, ficando assim incapazes de contribuir para a formação da noção contemporânea de legitimidade enquanto mediaçáo entre facticidade e validade. O que separa o fato e o direito é propriamente o tema de Direito e democracia, de modo que o pensamento do autor do Contrato social permite refletir sobre o passo que Kant náo ousou dar e que posteriormente Marx, a partir de Hegel, tornou excessivamente concreto, portanto, autoritário. Trata-se, dessa maneira, de retomar a condição de comunicação intersubjetiva para constituir os procedimentos democráticos sem cair na tentação totalitária da luta de classes. Com isso, o legislador do Contrato não é mais um agente jacobino, mas um pedagogo de açôes comunicativas. Habermas precisa, por conseguinte, renovar sua leitura anterior de Rousseau face à importância da educação em seu sistema político, tema fundamental na democracia contemporânea.

\section{I}

Em Mudança estrutural, Habermas analisa a formação do conceito de opinião pública para o qual a contribuição de Rousseau é relevante, além de ser o primeiro a empregar a expressão "opinion publique". Nessa obra, o Cidadão de Genebra é considerado adepto da "liberdade dos antigos" e contrário à "liberdade dos modernos", conforme caracterização feita por Benjamin

\footnotetext{
2 "Rousseau e Kant [...] empreenderam esforços com o objetivo de pensar tanto a vontade soberana quanto a razáo prática sob o conceito de autonomia da pessoa do direito, a tal ponto que no pensamento de ambos a soberania popular e os direitos humanos se interpretam mutuamente [...] Rousseau sugere uma leitura mais republicana, Kant uma leitura mais liberal" (HABERMAS, 2002, p.291). Há passagens em várias obras, por exemplo: (HABERMAS, 2003, I, p.134]
} 
Constant (cf. CONSTANT, 1997, p. 604-605), permitindo bem discriminar Rousseau e Kant, ambos com a mesma concepção de autonomia, a despeito de um privilegiar a vida pública e outro, a vida subjetiva. Segundo Habermas, o que funda a opinião pública em Rousseau é uma opinião não-pública, a do legislador, pois cabe a ele estabelecer o conteúdo do contrato. Tanto o povo quanto o público pensante estão excluídos, porque o povo "[...] se irritaria com as sutilezas da discussão política" e a elite pensante "[...] daria ênfase a interesses particulares" (HABERMAS, 1984, p.120). Por isso, a simplicidade deve evitar "discussóes espinhosas" contra o luxo que corrompe todos, uma vez que o luxo "[...] submete um grupo a outro e todos à opinião pública (et tous à l'opinion)" (HABERMAS, 1984, p.120). Habermas intercambia e mescla, ao citar e comentar Rousseau, as passagens em que o genebrino usa a expressão “opinion" e a expressão "opinion publique". Pergunta-se, em decorrência, por que Rousseau identifica a "soberana opiniấo popular” com a "opiniâo pública”. Apresenta entấo sua resposta:

A explicaçáo é simples. Uma democracia direta exige a presença real do soberano. A volonté générale como corpus mysticum está ligada ao corpus physicum do povo unânime reunido. A idéia do plebiscito permanente é concebida por Rousseau no quadro da polis grega: lá, o povo estava de algum modo reunido ininterruptamente na praça; assim também, aos olhos de Rousseau, a place publique se torna fundamento da constituição. Desta é que a opinion publique recebe seu atributo; portanto dos cidadáos reunidos para a aclamaçáo e não da argumentaçáo pública de um public éclairé. (HABERMAS, 1984, p. 121-122).

O modelo é a democracia antiga, em que as proposiçóes são aclamadas por todos, sem que as sutilezas da argumentação sejam analisadas, e em que o fundamento da constituição desemboca num corpo místico, já que o público esclarecido é apenas uma parte do soberano e todos votam. Cabe à unidade mística do povo, na figura do soberano, por meio do legislador, no fundo uma vontade não-pública, manifestar-se como porta-voz e ser recebido por aclamaçáo. Conclui Habermas: "Rousseau quer a democracia sem discussão pública”, ou, em outras palavras, a opiniāo pública é o “[...] mudo espírito do povo" (HABERMAS, 1984, p. 122 e 126). Assim, o legislador se eleva para dizer ao povo o que o povo quer.

Afirma Rousseau: "Os particulares discernem o bem que rejeitam, o público quer o bem que não discerne. Todos necessitam igualmente de guias. A uns é preciso conformar vontade à razão, e ao outro, ensinar a conhecer o 
que quer. [...] Eis donde nasce a necessidade de um legislador" (ROUSSEAU, 1978, p. 56). Habermas mostra alguns efeitos desse pensamento nas penas dos líderes da Revolução Francesa, em diversos sentidos. Em Marat e Robespierre, esse argumento pôde justificar o Terror. Habermas percebe que Rousseau não pode ser responsabilizado por isso, mas nota que Kant, observador da Revolução, o corrige nesse aspecto: "A argumentação de Kant segue completamente a de Rousseau, com uma decisiva excessão num ponto: que o princípio da soberania popular só pode ser realizado pressupondo-se um uso público da razáo" (HABERMAS, 1984, p. 131).

\section{II}

Numa obra mais recente, Direito e democracia, Habermas relê Rousseau preocupado com a lógica procedimental do direito e com a prática de uma democracia possível. Nesse contexto, surge uma novidade - a preocupação de Rousseau com a educação ética que condiciona a vida política - a virtude é um imperativo para o cidadão: "A descrição excepcionalista da prática política ideal sugere a necessidade de um lugar-tenente pedagógico" (HABERMAS, 2003, I, p. 345). É preciso educar o cidadão e reeducar o homem. Sem a educação, o homem não está preparado para a cidadania: "Esta imputação de virtude já levou Rousseau à separação entre o cidadão orientado para o bem público e o homem privado eticamente sobrecarregado; a unanimidade do legislador político deveria ser garantida previamente através de um consenso ético dos ânimos" (HABERMAS, 2003, I, p. 345). Nesse ponto, Habermas debate com Bernard Manin, que examina em artigo o procedimento democrático em Rousseau (cf. MANIN, 1985), e insiste que sua crítica a Rousseau fora feita em Mudança estrutural da esfera pública. Parece-nos, contudo, que a leitura aqui é um pouco diferente.

Em Direito e democracia, ao analisar Rousseau, Habermas aplica uma distinção entre ética e moral estabelecida por F. Michelman, segundo a qual a ética exprime uma vontade e a moral exprime um conhecimento ${ }^{3}$, ou seja, de um lado, uma vontade ético-política de uma comunidade, de outro, um saber

\footnotetext{
${ }^{3}$ Habermas afirma: "F. Michelmann observa na tradição constitucional americana uma tensão entre o domínio impessoal das leis, fundadas em direitos humanos naturais, e a auto-organização espontânea de uma comunidade, a qual se outorga suas leis através da vontade soberana do povo"(HABERMAS, 2003, I, p. 133). Domínio impessoal fundado em direito natural implica um conhecimento prédefinido, já auto-organização de vontade soberana pressupóe diversidade de vontades.
} 
moral ancorado num estado natural e universal. Sublinha Habermas: "Rousseau interpretou a idéia da autolegislação mais na linha da ética do que na da moral e entendeu a autonomia como a realização consciente da forma de vida de um povo concreto" (HABERMAS, 2003, I, p.136). Portanto, a autolegislação em Rousseau vincula-se mais a uma vontade do que a uma razão, mais a um querer do que a um saber. Em acréscimo, trata-se de um povo concreto, existente, não de um povo ideal ou idealizado. Em seguida, continua:

Rousseau descreveu a constituição da soberania de um povo, que se dá através de um contrato da sociedade, como um ato existencial da socialização, por meio do qual os indivíduos singulares, voltados ao sucesso, se transformam nos cidadãos de uma comunidade ética, orientada ao bem comum. (HABERMAS, 2003, I, p. 136).

Essa caracterização do contrato como ato existencial mostra bem o elemento fundante da soberania, a conversão de indivíduos singulares em cidadãos. Nesse momento fundante, a convenção só pode ser consensual e unânime. Se está em jogo a existência da sociedade, todos os povos concretos - cada um a sua maneira - estão concernidos. "Enquanto membros de um corpo coletivo, eles se diluem no grande sujeito de uma prática de legislação, o qual rompeu com os interesses singulares das pessoas privadas, submetidas às leis. Rousseau exagerou ao máximo a sobrecarga ética do cidadão, embutida no conceito republicano de sociedade" (HABERMAS, 2003, I, p. 136). Tratase de momento fundante, ato existencial da sociedade. A seguir, Habermas cita uma passagem do capítulo do Contrato social sobre o governo: "Quanto menos as vontades singulares se referirem à vontade geral - isto quer dizer, os costumes às leis - tanto mais convém que cresça o poder de coerção. Portanto, o governo, para ser bom, precisa ser tanto mais poderoso quanto maior for o número das pessoas" (i HABERMAS, 2003, I, p. 136). Cito novamente, pela tradução brasileira direta do francês: "Quanto menos se relacionem as vontades particulares com a vontade geral, isto é, os costumes com as leis, tanto mais deverá a força repressora aumentar. Conclui-se pois que o Governo, para ser bom, deve ser relativamente mais forte na medida em que o povo for mais numeroso" (ROUSSEAU, 1978, p. 76-77). Note que se trata aí apenas de regra geral numérica (presente em Montesquieu e muito outros) da relação entre governo e povo: quanto mais numeroso for o povo, maior poder e mais força precisa ter o governo, caso contrário, o povo se subdivide em povos menores, com governos capazes de administrá-los. Jamais a defesa do despotismo! Contudo, desse princípio geral Habermas deduz uma característica procedimental de 
todo governo em Rousseau: "Rousseau não pode explicar a possibilidade de uma mediação entre a requerida orientação pelo bem comum dos cidadãos e os interesses sociais diferenciados das pessoas privadas, ou melhor, não sabe dizer como é possível mediar, sem repressão, entre a vontade comum, construída normativamente, e o arbítrio dos sujeitos singulares" (HABERMAS, 2003, I, p. 137). E deduz: "Perde-se o sentido universalista do princípio do direito". De um lado, o governo é forte demais, sufoca vontades particulares; de outro, é fraco demais, é relativo à vontade e náo tem sentido universal baseado num princípio de direito, um princípio racional.

"O sentido da igualdade do conteúdo do direito, contido na pretensão de legitimidade do direito moderno, e que é o que interessa a Rousseau, não pode ser esclarecido suficientemente através das qualidades lógico-semânticas de leis gerais. A forma gramatical de mandamentos universais nada diz sobre sua validade" (HABERMAS, 2003, I, p. 137). É exatamente como pensa Rousseau, Habermas vê bem. A grande crítica vem a seguir:

"Rousseau pressente o conteúdo normativo do princípio do direito nas propriedades lógic-semânticas daquilo que é querido; este princípio só poderia ser vislumbrado nas condições pragmáticas que determinam como se forma a vontade política" (HABERMAS, 2003, I, p. 137). Perfeito, para Rousseau, a vontade não é refém da razão, mas da utilidade, isto é, em certo sentido, de condiçóes pragmáticas, de condições de uso. Mas COMO se forma a vontade política? Esta é a questão que mais preocupa Habermas, nesse texto: como? Quais os procedimentos? Para Habermas, são os procedimentos que darão legitimidade ao processo. Já Rousseau pensa que cada sociedade, cada povo concreto, estabelecerá procedimentos diferentes, diversos, por isso, não entra nessa questão - ou, quando entra, , por exemplo, nas Consideraçôes sobre o governo da Polônia, muitos comentadores encontram contradiçóes com o Contrato. ${ }^{4}$ Trata-se do que é sugerido para um povo concreto, no caso, a Polônia, em 1772.

Habermas situa melhor sua crítica a seguir, apropriando-se mais uma vez da fenomenologia (aliás, será que podemos ver aí uma crítica geral à fenomenologia?):

Sob premissas da filosofia da consciência, é possível aproximar a razão e a vontade no conceito de autonomia - porém essa capacidade da autodeterminação é atribuída a um sujeito - seja ao eu da Crítica da razão

${ }^{4}$ Cf., por exemplo, a excelente introdução de Jean Fabre às Oeuvres complètes de Rousseau, na Colletion Pléiade (FABRE, 1964) e em seu artigo nos Annales Rousseau (FABRE, 1962). 
pura, seja ao povo do Contrato social. [Em Kant] Se a vontade racional só pode formar-se no sujeito singular, então a autonomia moral dos sujeitos singulares deve passar através da autonomia política da vontade unida de todos, a fim de garantir antecipadamente, por meio do direito natural, a autonomia privada de cada um. [Em Rousseau] Se a vontade racional só pode formar-se no sujeito superdimensionado de um povo ou de uma nação, entâo a autonomia política deve ser entendida como a realização autoconsciente da essência ética de uma comunidade concreta; e a autonomia privada só é protegida contra o poder subjugador da autonomia política através da forma náo-discriminadora de leis gerais. Ambas [Kant e Rousseau] as concepçóes passam ao largo da força de legitimação de uma formação discursiva da opinião e da vontade, na qual são utilizadas as forças ilocucionárias do uso da linguagem orentada pelo entendimento, a fim de aproximar razáo e vontade - e para chegar a convicçóes nas quais todos os sujeitos singulares podem concordar entre si sem coerção. (HABERMAS, 2003, I, p. 137-138).

Ora, é a ação comunicativa resolvendo todos os problemas e renunciando à força. Mas o que interessa vem a seguir:

Todavia, se discursos e negociaçóes, cujos procedimentos são fundamentados discursivamente, constituem o lugar no qual se pode formar uma vontade racional, a legitimidade do direito apoia-se em última instância num arranjo comunicativo.

Assim, se a legitimidade do direito está na comunicação e se esta funda os procedimentos pelos quais se negocia, podemos dizer, por conseguinte, que são os meios que sustentam os fins. Para Rousseau (deixemos Kant de lado, por ora), é a vontade geral que confere legitimidade, por isso, os meios podem impor-se às vontades particulares (donde a importância da educação para formar e da punição para reeducar, conforme o "forçar a ser livre ").

Voltemos um pouco. Afirma Habermas:

Em Rousseau, o exercício da autonomia política não está mais sob reserva de direitos naturais; o conteúdo normativo dos direitos humanos dissolvese no modo de realizaçáo da soberania popular. Através do medium de leis gerais e abstratas, a vontade unificada dos cidadáos está ligada a um processo de legislação democrática que exclui per se todos os interesses nãouniversalizáveis, permitindo apenas regulamentaçóes que garantem a todos as mesmas liberdades subjetivas. De acordo com esta idéia, o exercício da 
soberania do povo, conforme ao procedimento, garante também a substância do direito humano originário. (HABERMAS, 2003, I, p. 135-136).

De fato, Rousseau exclui o direito natural e o substitui pelos direitos políticos, entre os quais o direito humano originário (ou direito natural prévio ao contrato) é retomado. O que nos interessa aqui é que é o exercício da autonomia, o exercício da soberania, se conforme a um procedimento universalizável, então garante a substância do direito humano originário. Note-se que é o procedimento, o exercício, que garante a substância, segundo Habermas, e não o fundamento do contrato anteriormente estabelecido por Rousseau.

Pensamos que, aqui, em Direito e democracia, a crítica não repete o que fora feito em Mudança estrutural. Nesta, o legislador é o fundamento da opinião pública do povo, infante, mudo. Na outra, é o exercício da soberania, por meio de procedimentos universalizáveis, que vai garantir a legitimidade. Habermas reconhece que a opiniáo pública em Rousseau não é uma entidade abstrata de fundamento, mas um conceito operativo e prático para a soberania.

MONTEAGUDO, Ricardo. Habermas as a reader of Rousseau. Trans/Form/Ação, Marília, v. 36, p. 195-204, 2013. Edição Especial.

ABSTRACT: We intend to show how Habermas' reading of Rousseau in The Structural Transformation of the Public Sphere (1962) is slightly revised in Between Facts and Norms (1992). This small change restructures the entire Habermasian conception of Rousseau's politics.

KEYWORDS: Habermas. Rousseau. Public sphere. Public opinion. Political rights. 


\section{REFERÊNCIAS}

CONSTANT, Benjamin. De la liberté des anciens comparée à celle des modernes. In: Écrits politiques. Paris: Gallimard, 1997.

FABRE, Jean. Introduction à Considérations sur le gouvernement de Pologne. In: ROUSSEAU, Jean-Jacques. Oeuvres Complètes, t.III. Collection Pléiade. Paris: Gallimard, 1964.

. Réalité et utopie dans la pensée politique de Rousseau. In: Annales Jean-Jacques Rousseau, t. XXXV, 1959-1962. Genebra: Société Rousseau, 1962.

HABERMAS, Jürgen. Mudança estrutural da esfera pública. Rio de Janeiro: Tempo Brasileiro, 1984

Direito e democracia: entre facticidade e validade. 2 tomos. Rio de Janeiro: Tempo Brasileiro, 2003. . A inclusão do outro: estudos de teoria política. São Paulo: Loyola, 2002.

MANIN, Bernard. Volonté générale ou délibération. Esquisse d'une théorie de la délibération politique. Revista Le débat, nº 33. Paris: Gallimard, jan/1985.

ROUSSEAU, Jean-Jacques. Contrato social. São Paulo: Abril, 1978 (Coleção Os Pensadores). 
MONTEAGUDO, R. 